\title{
Effects of Temperature and Salinity on Seed Germination of Three Common Grass Species
}

\author{
Yongjie Liu' ${ }^{1 *}$, Shuang Zhang ${ }^{1}$, Hans J. De Boeck ${ }^{2}$ and Fujiang Hou' \\ ${ }^{1}$ State Key Laboratory of Grassland Agro-Ecosystems, Key Laboratory of Grassland Livestock Industry Innovation, Ministry \\ of Agriculture and Rural Affairs, College of Pastoral Agriculture Science and Technology, Lanzhou University, Lanzhou, China, \\ ${ }^{2}$ Plants and Ecosystems (PLECO), Department of Biology, University of Antwerp, Wilrijk, Belgium
}

OPEN ACCESS

Edited by:

Quanzhen Wang,

Northwest A\&F University, China

Reviewed by:

Weiqiang Li,

RIKEN, Japan

Keliang Zhang,

Yangzhou University, China

*Correspondence:

Yongjie Liu

yj|@|zu.edu.cn

Specialty section:

This article was submitted to

Functional Plant Ecology,

a section of the journal

Frontiers in Plant Science

Received: 27 June 2021 Accepted: 12 November 2021 Published: 10 December 2021

Citation:

Liu Y, Zhang S, De Boeck HJ and Hou F (2021) Effects of Temperature and Salinity on Seed Germination of Three Common Grass Species.

Front. Plant Sci. 12:731433.

doi: 10.3389/fp/s.2021.731433
Temperature and salinity significantly affect seed germination, but the joint effects of temperature and salinity on seed germination are still unclear. To explore such effects, a controlled experiment was conducted, where three temperature levels (i.e., 15, 20, and $25^{\circ} \mathrm{C}$ ) and five salinity levels (i.e., 0, 25, 50, 100, and $200 \mathrm{mmol} / \mathrm{L}$ ) were crossed, resulting in 15 treatments (i.e., 3 temperature levels $\times 5$ salinity levels). Three typical grass species (Festuca arundinacea, Bromus inermis, and Elymus breviaristatus) were used, and 25 seeds of each species were sown in petri dishes under these treatments. Germination percentages and germination rates were calculated on the basis of the daily recorded germinated seed numbers of each species. Results showed that temperature and salinity significantly affected seed germination percentage and germination rate, which differed among species. Specifically, F. arundinacea had the highest germination percentage, followed by $E$. breviaristatus and B. inermis, with a similar pattern also found regarding the accumulated germination rate and daily germination rate. Generally, F. arundinacea was not sensitive to temperature within the range of $15-25^{\circ} \mathrm{C}$, while the intermediate temperature level improved the germination percentage of $B$. inermis, and the highest temperature level benefited the germination percentage of $E$. breviaristatus. Moreover, F. arundinacea was also not sensitive to salinity within the range of $0-$ $200 \mathrm{mmol} / \mathrm{L}$, whereas high salinity levels significantly decreased the germination percentage of $B$. inermis and $E$. breviaristatus. Thus, temperature and salinity can jointly affect seed germination, but these differ among plant species. These results can improve our understanding of seed germination in saline soils in the face of climate change.

Keywords: germination percentage, germination rate, grass species, salinity, temperature

\section{INTRODUCTION}

Seed germination is a fundamental stage in the life cycle of a plant (Bewley, 1997; Nimbalkar et al., 2020). Seed germination is significantly affected by both physical and biological factors such as temperature and species identity (Larsen et al., 2004; Bewley et al., 2013; Zhang et al., 2020). Soil salinization is one of the major drivers of soil degradation (Zhang et al., 2015a; 
Gorji et al., 2017), and it can significantly affect seed germination and the following stages such as seedling establishment (Khan and Gulzar, 2003; Qu et al., 2008). Over 900 Mha land is impacted by salinity in the whole world (Rengasamy, 2006; Shiade and Boelt, 2020). Climate change such as extreme warming is expected to be more frequent in the future (Khan and Qaiser, 2006; Blackport and Screen, 2020; Bai et al., 2021). Such change could significantly affect seed germination (Walck et al., 2011; Mondoni et al., 2012). Soil salinization could become more serious in the face of climate change because global warming generally increases evaporation, which can promote soil salinization (Utset and Borroto, 2001). Therefore, salinity and temperature would jointly affect seed germination, especially in the arid and semi-arid areas of northeastern China, where the soil salinization area covers over $70 \%$ of the total land area (Wang et al., 2011). Moreover, several species are facing population reductions due to human disturbances and climate change (Richmond et al., 2007; Ureta et al., 2012; Gu et al., 2018). Thus, exploring seed germination under the ongoing soil salinization and global warming is important in assessing the stability of plant community.

Theoretically, the seed germination of each species has an optimal temperature, under which seeds could germinate better than under other temperatures. Previous studies found that salinity decreased seed germination of some species compared with non-saline conditions (Khan and Gulzar, 2003; Qu et al., 2008). However, the impact of salinity on seed germination might be modified by temperature, as Gorai and Neffati (2007) found that negative effects of salinity on seed germination were less severe at the optimum temperature, as the additional environmental stress at low or high temperatures would thus be alleviated (Al-Khateeb, 2006). Yet, Khan and Ungar (2001) found that the effect of salinity was stronger at lower temperatures, while Delesalle and Blum (1994) revealed that such effect was stronger at higher temperatures. Finally, Khan and Ungar (1998) showed that the effect of salinity was not affected by temperature in their experiment. Thus, the joint effects of salinity and temperature on seed germination are still unclear (Fernandez et al., 2015; Lin et al., 2018).

In response to local salinity and suboptimal temperatures, plant species developed different strategies, including adjusting germination percentage or germination rate through modifying seed dormancy and/or seed viability (Ungar, 1995; Khan et al., 2001; Khan and Ungar, 2001; Shahba et al., 2008; Guan et al., 2009). Such responses can further alter seedling establishment and seedling growth ( $\mathrm{Gu}$ et al., 2018; Del Vecchio et al., 2021). Exploring the effects of salinity and temperature on seed germination may shed light on understanding the mechanisms of species coexistence. However, studying such effects under natural conditions is difficult since (1) soil conditions such as temperature and salinity vary spatially and temporally (Hermans et al., 2016), which makes it difficult to keep a constant level of temperature or salinity. (2) Other environmental variables such as radiation and soil moisture hamper separating the roles of temperature and salinity from these factors (Khan and Ungar, 1997; De Boeck et al., 2015; Borja et al., 2016; Bhatt et al., 2020). (3) Some particular species in a community such as halophytes and xerophytes may skew the results, where halophytes can modify their strategies (e.g., reduce seed germination percentage or delay the start of germination under the high level of salinity) to adapt to different salinity levels (Gulzar and Khan, 2001; Khan and Gul, 2006; El-Keblawy et al., 2020), and xerophytes can grow well under conditions with a large variation of temperature (Zhang et al., 2015b).

To explore the joint effects of temperature and salinity on seed germination of grass species with less confounding factors (Figure 1), a controlled experiment was thus conducted. Three typical grass species (Festuca arundinacea, Bromus inermis, and Elymus breviaristatus) widely used as forage species ( $\mathrm{Lu}$ et al., 2008) that can be potentially grown in saline soils were exposed to three levels of temperature and five levels of salinity. Specifically, (1) we expect seed germination in general to be the highest at the intermediate level of temperature $\left(20^{\circ} \mathrm{C}\right)$, which is thought to be closest to the optimal temperature for seed germination for such grasses (Romo and Eddleman, 1995; Lu et al., 2008; Zhang et al., 2013). (2) We assume that seed germination would consistently decrease with increasing salinity (Wu et al., 2015; Zhang and Dai, 2019). (3) We anticipate that the intermediate (and supposed optimum) temperature level would alleviate the negative effects of salinity on seed germination (Gorai and Neffati, 2007).

\section{MATERIALS AND METHODS}

\section{Experimental Design}

To explore the effects of temperature and salinity on seed germination, an experiment was conducted at the Yuzhong Campus of Lanzhou University, China $\left(104^{\circ} 09^{\prime} 44^{\prime \prime} \mathrm{N}\right.$, $35^{\circ} 56^{\prime} 55^{\prime \prime} \mathrm{E}$ ) from 6 April to 25 April 2021. Three levels of temperature (i.e., 15,20 , and $25^{\circ} \mathrm{C}$ ) and five levels of salinity (i.e., $\mathrm{NaCl}$ concentration $0,25,50,100$, and $200 \mathrm{mmol} / \mathrm{L}$ ) were created to simulate the future climatic conditions. Note that these

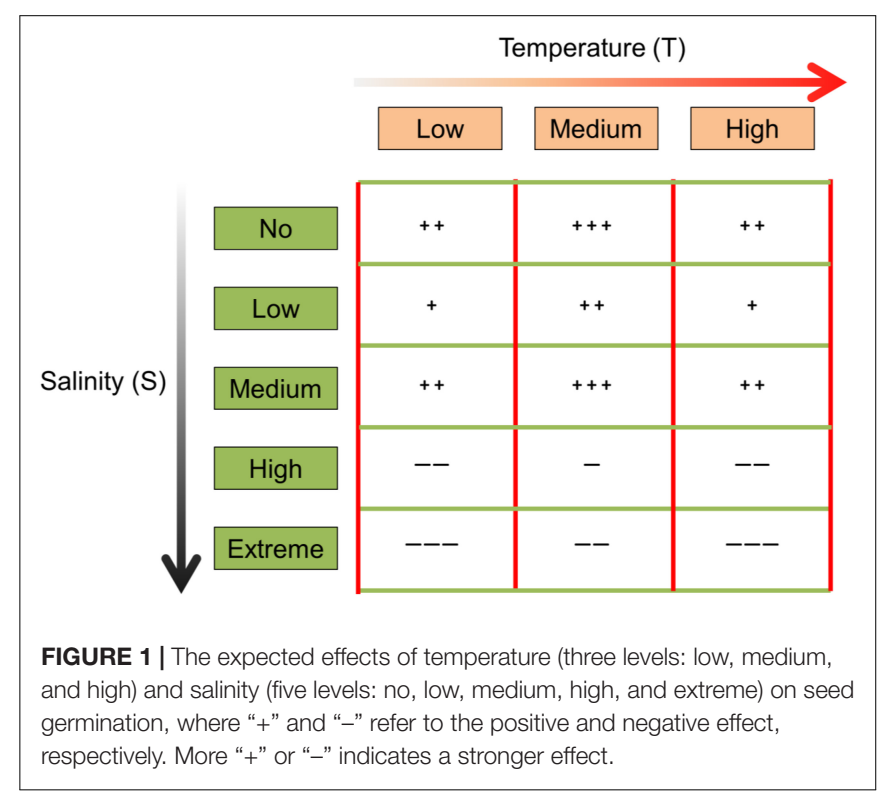


temperature and salinity levels were set in line with previous studies (Lu et al., 2008 and Zhang et al., 2013 for temperature levels; Yang et al., 2009 and Li et al., 2019 for salinity levels). Three target grass species ( $F$. arundinacea, B. inermis, and E. breviaristatus) were exposed to these 15 treatments. A recent study reported that different varieties of a species responded differently to salinity stress (Shiade and Boelt, 2020). However, this study aimed to explore the responses of seed germination of different species to the joint effects of temperature and salinity, not of varieties of specific species. Seeds of the three species used in our experiment were bought from a commercial company (Best, Beijing, China). Further information can be found in Table 1. Twenty-five seeds of each species were applied in each treatment. All seeds were evenly sown in petri dishes with two sheets of filter paper (diameter $7 \mathrm{~cm}$ ). The filter paper was saturated with saline solutions (around $5 \mathrm{~mL}$ ) and kept stable during the experiment.

Three incubators (LRH-250-G, Illuminating Incubator) were used, and each of them was set at one of the three applied temperature levels. Petri dishes with the five salinity levels were randomly stored in each of these chambers. These petri dishes were covered with lids at the beginning of the experiment, and they were removed after the germination of the seeds since lids impeded the growth of these seedlings. Five replicates were used per treatment, resulting in 225 petri dishes (i.e., 3 species $\times 3$ temperature levels $\times 5$ salinity levels $\times 5$ replications) in total. Note that the seed germination test was conducted according to the rules of the International Seed Testing Associations (ISTA, 2018), and the germinated seeds in each petri dish were daily recorded. Seeds were treated as germinated when the radicle was more than $2 \mathrm{~mm}$ long (Shiade and Boelt, 2020). This experiment was ended when there was no additional germination for 3 days.

\section{Data Analysis and Statistics}

Germination percentage (GP) was calculated by dividing the germinated seed number by the total seed number in each petri dish along the experimental period. Accumulated germination rate (AGR) and daily germination rate (DGR) in each petri dish were calculated by the following two equations:

AGR $=\left(\sum G P_{i}\right) / i$, where $i$ is the day after seed set in these chambers;

DGR $=$ the newly germinated seed number per day/25 in each petri-dish.

To explore the seed germination during the experiment, four separate analyses were conducted. First, repeated-measures
ANOVA was used to explore the differences of GP, AGR, and DGR among the target species. Second, repeated-measures ANOVAs were applied to investigate the effects of temperature, species, and their interactions on the GP. Third, repeatedmeasures ANOVAs were employed to test the effects of salinity, species, and their interactions on the GP. A significant effect of species was found in the second and third analyses. Thus, separate repeated-measures ANOVAs analyses were conducted for each species, where temperature (or salinity), time, and their interaction were treated as variables. Fourth, MANOVA was performed to examine the impacts of temperature, salinity, species and their interactions on the GP, AGR at the last day of the experiment, and the average DGR during the experiment. Note that time (i.e., the germination date) was treated as an extra factor in these analyses except the last one.

Curve estimations were conducted to explore the relationships between salinity and GP separated by temperature, where linear, quadratic, power, and exponential curves were tested. A better model was identified with a lower Akaike Information Criterion (AIC) and a significant $P$-value. All statistics were performed with SPSS 23.0 (IBM Corp, 2015).

\section{RESULTS}

In the first analysis, GP, AGR, and DGR varied within species, germination date, and species $\times$ germination date interaction (Table 2 and Figure 2). On average, the GP of $F$. arundinacea was higher than that of E. breviaristatus and $B$. inermis, and the GP of E. breviaristatus was in turn higher than that of $B$. inermis (Figure 2A). Such a pattern was also found for AGR (Figure 2B) and DGR (Figure 2C). B. inermis germinated faster at the beginning of the experiment, while its germination decreased faster than the other two species during the experiment (Figure 2C). The interaction effect between species and germination date was likely caused by the convergence of the seed germination (Figure 2).

In the second analysis, on investigating the effects of species, temperature, and their interaction on GP, the three target species demonstrated different responses (Table 3 and Figure 3). The GP of $F$. arundinacea was not sensitive to the relatively high levels of temperature (Figure 3A). The GP of $B$. inermis was highest at the intermediate temperature level (Figure 3B), and the GP of E. breviaristatus was highest at the highest temperature level in this study (Figure 3C).

TABLE 1 | Information of the seeds applied in this experiment.

\begin{tabular}{|c|c|c|c|c|c|c|c|}
\hline Species & Variety name & $\begin{array}{c}\text { Standard germination } \\
\text { percentage }(\%)\end{array}$ & Seed color & 1,000 grain weight $(\mathrm{g})$ & Length (mm) & Width (mm) & Thickness (mm) \\
\hline Festuca arundinacea & Niuniu & $>85$ & Dark gray & $2.6 \pm 0.1$ & $7.0 \pm 0.8$ & $1.6 \pm 0.1$ & $0.9 \pm 0.1$ \\
\hline Bromus inermis & Normal & $>85$ & Brown & $4.1 \pm 0.1$ & $9.5 \pm 0.6$ & $1.8 \pm 0.1$ & $0.7 \pm 0.1$ \\
\hline Elymus breviaristatus & Normal & $>80$ & Light gray & $5.6 \pm 0.1$ & $11.7 \pm 1.5$ & $1.7 \pm 0.1$ & $1.7 \pm 0.1$ \\
\hline
\end{tabular}

"Normal" in the variety name reflects that there is no specific variety for this species. 

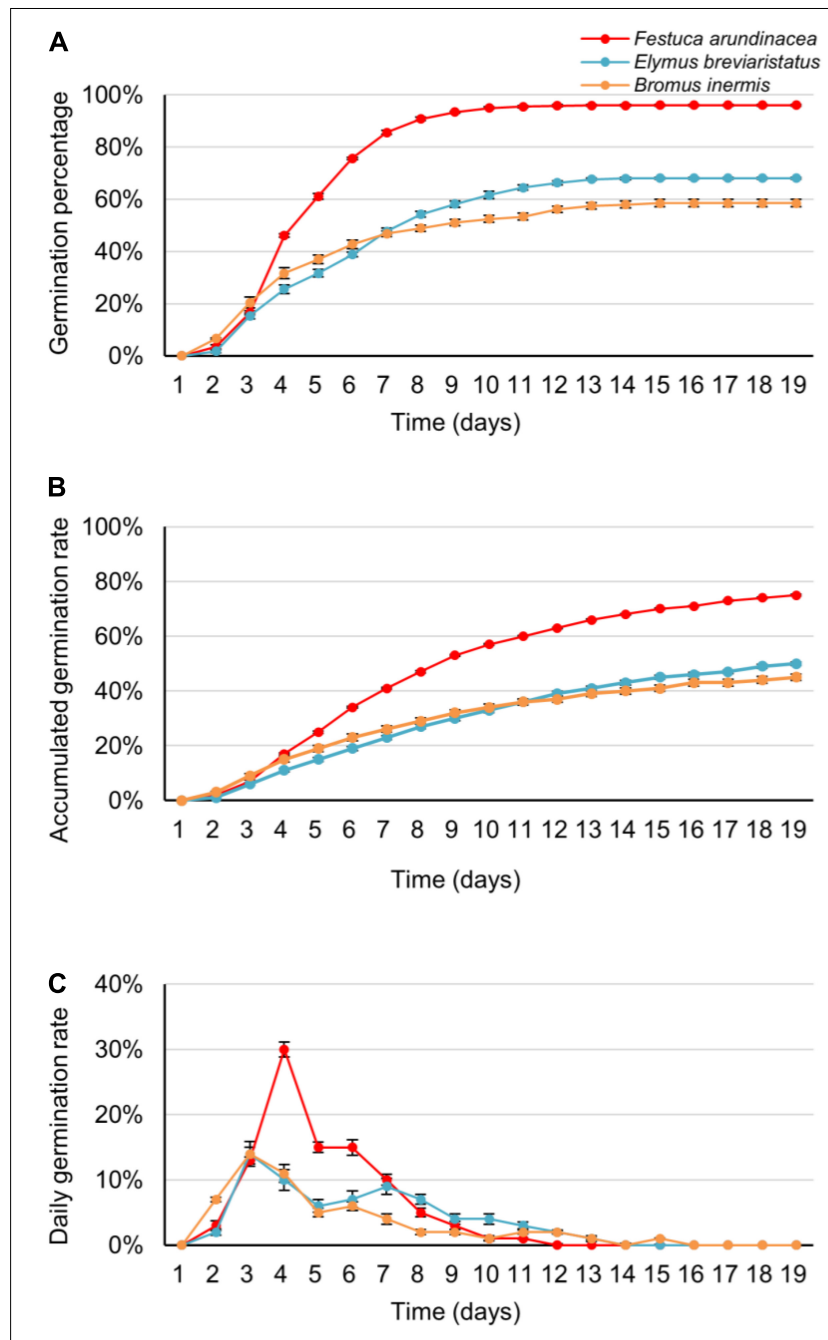

FIGURE 2 | The germination percentage (A), accumulated germination rate (B), and daily germination rate (C) of the three target grass species (Festuca arundinacea, Bromus inermis, and Elymus breviaristatus, labeled as red, orange, and blue color, respectively) along time (i.e., the germination date). Note that these figures are derived from the average data of the three temperature levels and five salinity levels.

In the third analysis, on testing the effects of species, salinity, and their interaction on GP, the three target species likewise showed different patterns (Table 4 and Figure 3).
The GP of F. arundinacea was not sensitive to relatively low levels of salinity. However, the other two species showed a different pattern, where the higher salinity levels decreased the GP of $B$. inermis, while the intermediate level of salinity increased. The GP of E. breviaristatus consistently decreased with increasing salinity levels. Moreover, the intermediate temperature level (i.e., $20^{\circ} \mathrm{C}$ ) $\times$ lowest salinity level (i.e., $0 \mathrm{mmol} / \mathrm{L})$ generated the highest GP for $F$. arundinacea, while the highest temperature level (i.e., $25^{\circ} \mathrm{C}$ ) $\times$ lowest salinity level (i.e., $0 \mathrm{mmol} / \mathrm{L}$ ) generated the highest GP for $B$. inermis and E. breviaristatus (Figure 4).

Finally, exploring the effects at the last day of the experiment, species, temperature, salinity, species $\times$ temperature, species salinity, and species $\times$ temperature $\times$ salinity significantly affected GP, AGR, and DGR (Table 5 and Figure 4), while there were no significant temperature $\times$ salinity effects at this measurement data.

\section{DISCUSSION}

The first hypothesis stated that seed germination would be the highest at the intermediate level of temperature. This was partly supported as such a pattern was found in one of the target plant species (i.e., B. inermis, Figure 3B), where lower germination was found at lower temperatures. This is partly consistent with the finding of Ao et al. (2014), where seed germination of $B$. inermis was low at lower temperatures. Note that such a pattern was not found in the other two target species. For F. arundinacea, temperature levels in this study may have all been in the optimal temperature range of this species (Lu et al., 2008), while for E. breviaristatus, the optimal temperature of seed germination might have been higher than the temperature levels we set (Figure 3C).

Our second hypothesis aimed to test whether seed germination would be reduced at higher levels of salinity. This was supported as seed germination of the three target species was generally lower at higher salinity levels, even though they responded inconsistently to the salinity gradient (Figure 3). Such results are in line with previous studies on the target species F. arundinacea (Shiade and Boelt, 2020), B. inermis (Yang et al., 2009). and E. breviaristatus (Li et al., 2019), and on other species such as Helianthus annuus (Wu et al., 2015), Oryza sativa (Xu et al., 2011), and Zea mays (Khodarahmpour et al., 2012). Such results could be related to the effects of ion toxicity on seed

TABLE 2 | Effects of species, time, and their interaction in repeated-measures ANOVA of germination percentage (GP), accumulated germination rate (AGR), and daily germination rate (DGR).

\begin{tabular}{|c|c|c|c|c|c|c|c|c|c|}
\hline & \multicolumn{3}{|c|}{ GP } & \multicolumn{3}{|c|}{ AGR } & \multicolumn{3}{|c|}{ DGR } \\
\hline & df & $F$ & $P$ & df & $F$ & $P$ & df & $\boldsymbol{F}$ & $P$ \\
\hline Time & 18,144 & 5304.4 & $<0.001$ & 18,144 & 14991.4 & $<0.001$ & 18,144 & 163.7 & $<0.001$ \\
\hline Species $\times$ Time & 36,144 & 164.5 & $<0.001$ & 36,144 & 267.9 & $<0.001$ & 36,144 & 20.4 & $<0.001$ \\
\hline
\end{tabular}

$F$-values, $P$-values, and degrees of freedom (df $f_{\text {between-groups, }} d f_{\text {within-groups }}$ ) are given with significant results $(P<0.05)$ in bold. 

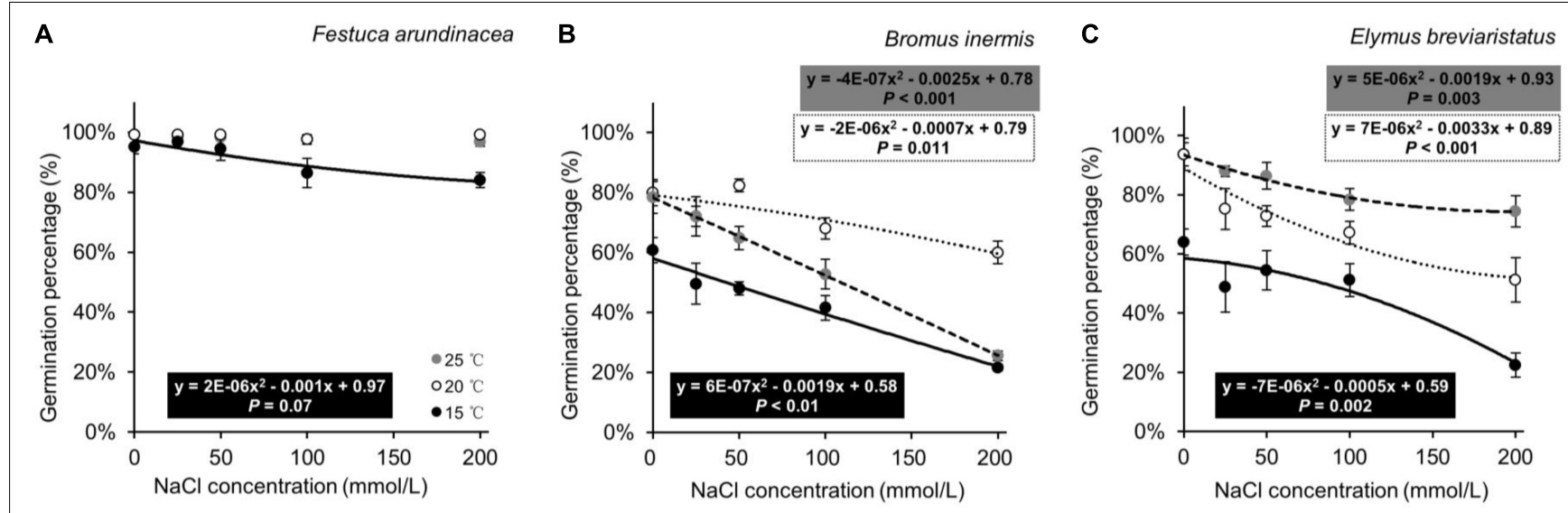

FIGURE 3 | Seed germination percentages of Festuca arundinacea (A), Bromus inermis (B), and Elymus breviaristatus (C) under different temperatures as a function of salinity levels. Note that all these significant equations are non-linear, so $P$-values are given.

TABLE 3 | Effects of species, temperature, time, and their interactions in repeated-measures ANOVA of germination percentage, which was separated by species since it was a significant factor.

\begin{tabular}{|c|c|c|c|}
\hline \multirow[t]{2}{*}{ Source } & \multicolumn{3}{|c|}{ Germination percentage } \\
\hline & df & $\boldsymbol{F}$ & $P$ \\
\hline Species & 2,384 & 281.5 & $<0.001$ \\
\hline Temperature & 2,384 & 661.7 & $<0.001$ \\
\hline Time & 18,384 & 4309.1 & $<0.001$ \\
\hline Species $\times$ Temperature & 4,384 & 10.5 & 0.001 \\
\hline Species $\times$ Time & 36,384 & 122.8 & $<0.001$ \\
\hline Temperature $\times$ Time & 36,384 & 155.8 & $<0.001$ \\
\hline Species $\times$ Temperature $\times$ Time & 72,384 & 24.9 & $<0.001$ \\
\hline \multicolumn{4}{|l|}{ Festuca arundinacea } \\
\hline Temperature & 2,144 & 370.3 & $<0.001$ \\
\hline Time & 18,144 & 4906.3 & $<0.001$ \\
\hline Temperature $\times$ Time & 36,144 & 86.3 & $<0.001$ \\
\hline \multicolumn{4}{|l|}{ Bromus inermis } \\
\hline Temperature & 2,144 & 122.3 & $<0.001$ \\
\hline Time & 18,144 & 650.3 & $<0.001$ \\
\hline Temperature $\times$ Time & 36,144 & 43.3 & $<0.001$ \\
\hline \multicolumn{4}{|l|}{ Elymus breviaristatus } \\
\hline Temperature & 2,144 & 75.5 & $<0.001$ \\
\hline Time & 18,144 & 2332.6 & $<0.001$ \\
\hline Temperature $\times$ Time & 36,144 & 28.0 & $<0.001$ \\
\hline
\end{tabular}

F-values, $P$-values, and degree of freedom ( $\left.d f_{\text {between-groups, }} d f_{\text {within-groups }}\right)$ are given with significant results $(P<0.05)$ in bold.

germination (Panuccio et al., 2014). The different responses of plants to salinity are likely caused by the genetic traits of these species (Vu et al., 2015; Chamorro et al., 2017) and their growing conditions (Mira et al., 2017).

The last hypothesis focused on the joint effects of salinity and temperature on seed germination, and we expected that the negative effect of salinity on seed germination would be alleviated at the intermediate level of temperature. This was supported by our findings in one of the three target species (B. inermis,
Figure 3B), where the germination percentage of $B$. inermis at the intermediate temperature level was higher than at the other two temperature levels, and the germination percentage decreased more slowly with increasing salinity compared with the other two temperature levels. This is in line with the finding of Gorai and Neffati (2007), where the negative effect of salinity on seed germination was alleviated at the optimum temperature. However, the other two species did not show such a pattern.

Results of this study should be interpreted and extrapolated with caution because of the following two reasons. One is

TABLE 4 | Effects of species, salinity, time, and their interactions in repeated-measures ANOVA of germination percentage, which was separated by species since it was a significant factor.

\begin{tabular}{lccc}
\hline Source & \multicolumn{3}{c}{ Germination percentage } \\
\cline { 2 - 4 } & Df & $\boldsymbol{F}$ & $\boldsymbol{P}$ \\
\hline Species & 2,720 & 380.4 & $<\mathbf{0 . 0 0 1}$ \\
Salinity & 4,720 & 132.3 & $<\mathbf{0 . 0 0 1}$ \\
Time & 18,720 & 4258.7 & $<\mathbf{0 . 0 0 1}$ \\
Species $\times$ Salinity & 8,720 & 7.1 & $\mathbf{0 . 0 0 1}$ \\
Species $\times$ Time & 36,720 & 167.0 & $<\mathbf{0 . 0 0 1}$ \\
Salinity $\times$ Time & 72,720 & 27.0 & $<\mathbf{0 . 0 0 1}$ \\
Species $\times$ Salinity $\times$ Time & 144,720 & 5.7 & $<\mathbf{0 . 0 0 1}$ \\
Festuca arundinacea & & & \\
Temperature & 4,288 & 24.0 & $<\mathbf{0 . 0 0 1}$ \\
Time & 18,288 & 4829.5 & $<\mathbf{0 . 0 0 1}$ \\
Temperature $\times$ Time & 72,288 & 13.8 & $<\mathbf{0 . 0 0 1}$ \\
Bromus inermis & & & \\
Temperature & 4,288 & 57.0 & $<\mathbf{0 . 0 0 1}$ \\
Time & 18,288 & 667.2 & $<\mathbf{0 . 0 0 1}$ \\
Temperature $\times$ Time & 72,288 & 16.7 & $<\mathbf{0 . 0 0 1}$ \\
Elymus breviaristatus & & & $<\mathbf{0 . 0 0 1}$ \\
Temperature & 4,288 & 34.4 & $<\mathbf{0 . 0 0 1}$ \\
Time & 18,288 & 1266.5 & $\mathbf{0 . 0 0 1}$ \\
Temperature $\times$ Time & 72,288 & 9.4 & \\
\hline F-vales, Prals, & & &
\end{tabular}

F-values, $P$-values, and degree of freedom ( $\left.d f_{\text {between-groups, }} d f_{\text {within-groups }}\right)$ are given with significant results $(P<0.05)$ in bold. 

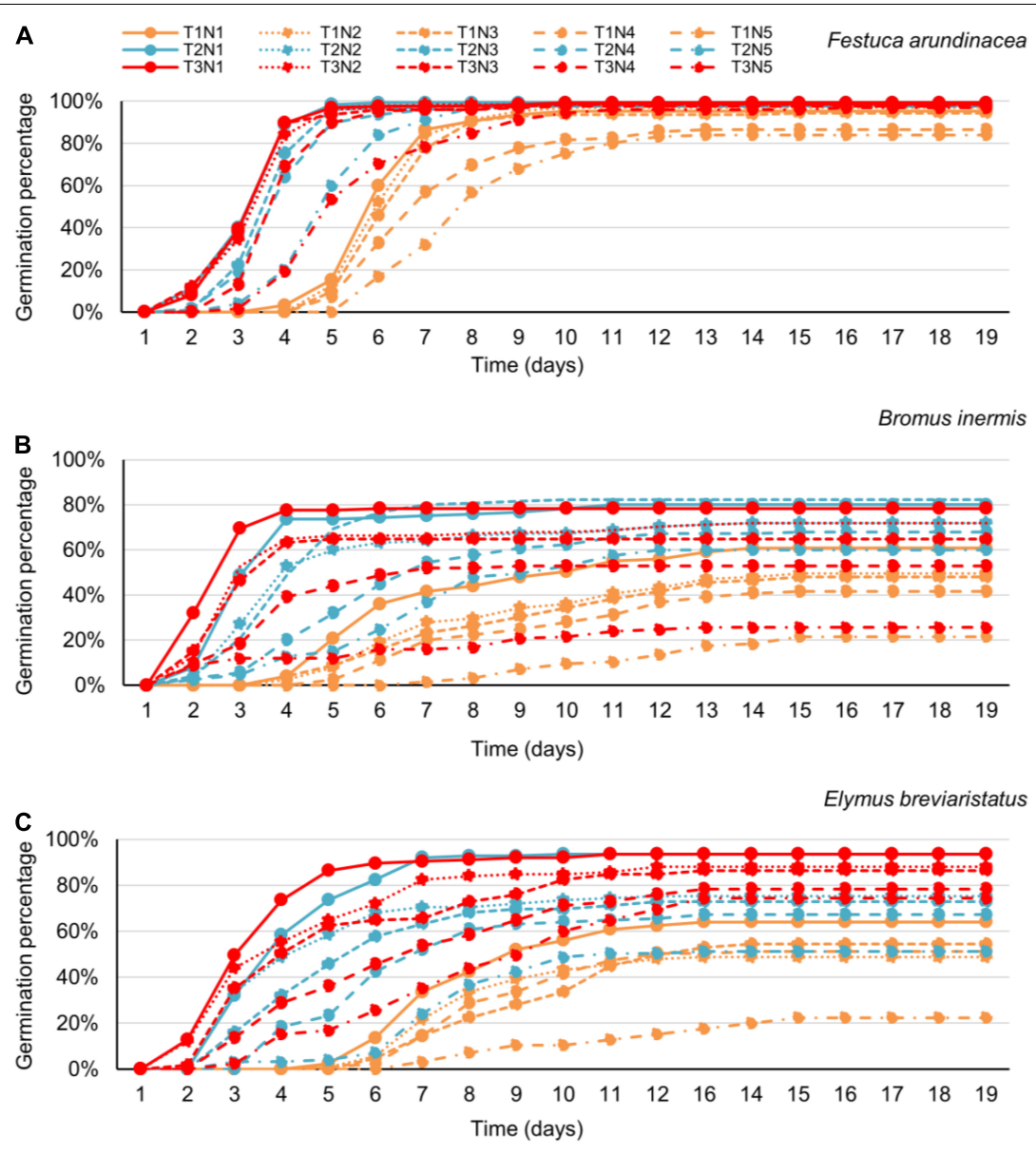

FIGURE 4 | The joint effect of temperature and salinity on seed germination of Festuca arundinacea (A), Bromus inermis (B), and Elymus breviaristatus (C) as a function of time (i.e., the germination date). Note that $\mathrm{T} 1-\mathrm{T} 3$ refer to the three temperature levels, that is, 15,20 , and $25^{\circ} \mathrm{C}$, respectively, while $\mathrm{N} 1-\mathrm{N} 5$ reflect the five salinity levels, that is, $0,25,50,100$, and $200 \mathrm{mmol} / \mathrm{L}$, respectively.

TABLE 5 | Effects of temperature, salinity, species, and their interactions in MANOVA of germination percentages (GP), accumulated germination rate (AGR), and daily germination rate (DGR).

\begin{tabular}{|c|c|c|c|c|c|c|c|c|c|}
\hline & \multicolumn{3}{|c|}{ GP } & \multicolumn{3}{|c|}{ AGR } & \multicolumn{3}{|c|}{ DGR } \\
\hline Temperature & 2,180 & 102.3 & $<0.001$ & 2,180 & 268.2 & $<0.001$ & 2,180 & 193.0 & $<0.001$ \\
\hline Salinity & 4,180 & 42.7 & $<0.001$ & 4,180 & 79.3 & $<0.001$ & 4,180 & 60.7 & $<0.001$ \\
\hline Species $\times$ Temperature & 4,180 & 13.0 & $<0.001$ & 4,180 & 5.9 & $<0.001$ & 4,180 & 10.3 & $<0.001$ \\
\hline Species $\times$ Temperature $\times$ Salinity & 16,180 & 1.6 & 0.080 & 16,180 & 1.1 & 0.335 & 16,180 & 2.4 & 0.003 \\
\hline
\end{tabular}

$F$-values, $P$-values, and degrees of freedom ( $d f_{\text {between-groups, }} d f_{\text {within-groups }}$ ) are given, with significant results $(P<0.05)$ in bold.

that $\mathrm{NaCl}$ solutions in this study might evaporate at different rates when they were set under different temperatures during the experiment (Sayer et al., 2017), and this may affect the ultimate salinity level and thus the ensuing results. The other is that each level of temperature was kept constant during the experiment in this study, while previous studies found that variation of temperature can benefit seed germination (Liu et al., 2013, 2017a; Spindelböck et al., 2013; Burghardt et al., 2016). Moreover, soil resources such as soil temperature and salinity vary a lot even at a short distance in natural conditions (Maestre et al., 2003; Lundholm, 2010). Thus future studies on seed germination should consider the heterogeneous 
distributions of these factors, potentially in combination with other aspects of soil heterogeneity (e.g., Liu et al., 2017b,c, 2019; Liu and Hou, 2021).

\section{DATA AVAILABILITY STATEMENT}

The original contributions presented in the study are included in the article/supplementary material, further inquiries can be directed to the corresponding author.

\section{AUTHOR CONTRIBUTIONS}

YL designed the study, conducted the analyses, and wrote the first draft of the manuscript. SZ collected the data. All authors contributed significantly to the manuscript.

\section{REFERENCES}

Al-Khateeb, S. A. (2006). Effect of salinity and temperature on germination, growth and ion relations of Panicum turgidum Forssk. Bioresour. Technol. 97, 292-298. doi: 10.1016/j.biortech.2005.02.041

Ao, M., Miura, R., and Tominaga, T. (2014). Germination characteristics of four common perennial grasses of Inner Mongolian grassland, China. Grassl. Sci. 60, 9-14. doi: 10.1111/grs.12043

Bai, H., Xiao, D., Wang, B., Liu, D., Feng, P., and Tang, J. (2021). Multi-model ensemble of CMIP6 projections for future extreme climate stress on wheat in the North China plain. Int. J. Climatol. 41, E171-E186.

Bewley, J. D. (1997). Seed germination and dormancy. Plant Cell 9, 1055-1066.

Bewley, J. D., Bradford, K., and Hilhorst, H. (2013). Seeds: Physiological of Development, Germination and Dormancy, 3rd Edn, New York, NY: Springer, 407.

Bhatt, A., Gairola, S., Caron, M. M., Santo, A., Murru, V., El-Keblawy, A., et al. (2020). Effects of light, temperature, salinity, and maternal habitat on seed germination of Aeluropus lagopoides (Poaceae): an economically important halophyte of arid Arabian deserts. Botany 98, 117-125.

Blackport, R., and Screen, J. A. (2020). Insignificant effect of Arctic amplification on the amplitude of midlatitude atmospheric waves. Sci. Adv. 6:eaay2880. doi: $10.1126 /$ sciadv.aay2880

Borja, J., Fernando, A. O. S., Alessandra, F., Peter, P., and Lucy, E. C. (2016). Seed germination traits can contribute better to plant community ecology. J. Veg. Sci. 27, 637-645. doi: 10.1111/jvs. 12375

Burghardt, L. T., Edwards, B. R., and Donohue, K. (2016). Multiple paths to similar germination behavior in Arabidopsis thaliana. New Phytol. 209, 1301-1312. doi: 10.1111/nph.13685

Chamorro, D., Luna, B., and Moreno, J. M. (2017). Germination responses to current and future temperatures of four seeder shrubs across a latitudinal gradient in western Iberia. Am. J. Bot. 104, 83-91. doi: 10.3732/ajb.1600278

De Boeck, H. J., Vicca, S., Roy, J., Nijs, I., Milcu, A., Kreyling, J., et al. (2015). Global change experiments: challenges and opportunities. Bioscience 65, 922-931.

Del Vecchio, S., Mattana, E., Ulian, T., and Buffa, G. (2021). Functional seed traits and germination patterns predict species coexistence in Northeast Mediterranean foredune communities. Ann. Bot. 127, 361-370. doi: 10.1093/ aob/mcaa186

Delesalle, V. A., and Blum, S. (1994). Variation in germination and survival among families of Sagittaria latifolia in response to salinity and temperature. Int. J. Plant Sci. 155, 187-195.

El-Keblawy, A., Elnaggar, A., Tammam, A., and Mosa, K. A. (2020). Seed provenance affects salt tolerance and germination response of the habitatindifferent Salsola drummondii halophyte in the arid Arabian deserts. Flora 266:151592. doi: 10.1016/j.flora.2020.151592

\section{FUNDING}

This work was supported by the Key Research and Development Program of Forestry and Grassland Administration of Ningxia. Hui Autonomous Region, China "Study on Construction Mode and Key Technology of Grassland Ecological Civilization Demonstration Area in Ningxia Hui Autonomous Region". YL holds a start-up fund from Lanzhou University (508000561119213).

\section{ACKNOWLEDGMENTS}

We would like to thank Yan Zhang, Sixia Liu, and Qingyu Du for the experimental assistance. We would also like to thank Zhixia Ying for her valuable comments on the earlier versions of this manuscript.

Fernandez, I. C. D., Luque, E. G., Mercado, F. G., and Marrero, J. M. (2015). Germination responses of Limonium insigne (Coss.) Kuntze to salinity and temperature. Pak. J. Bot. 47, 807-812.

Gorai, M., and Neffati, M. (2007). Germination responses of Reaumuria vermiulata to salinity and temperature. Ann. Appl. Biol. 151, 53-59.

Gorji, T., Sertel, E., and Tanik, A. (2017). Monitoring soil salinity via remote sensing technology under data scare conditions: a case study from Turkey. Ecol. Indic. 74, 384-391.

Gu, R., Zhou, Y., Song, X., Xu, S., Zhang, X., Lin, H., et al. (2018). Effects of temperature and salinity on Ruppia sinensis seed germination, seedling establishment and seedling growth. Mar. Pollut. Bull. 134, 177-185. doi: 10. 1016/j.marpolbul.2017.08.013

Guan, B., Zhou, D., Zhang, H., Tian, Y., Japhet, W., and Wang, P. (2009). Germination responses of Medicago ruthenica seeds to salinity, alkalinity, and temperature. J. Arid. Environ. 73, 135-138. doi: 10.1016/j.jaridenv.2008.08.009

Gulzar, S., and Khan, M. A. (2001). Seed germination of a halophytic grass Aeluropus lagopoides. Ann. Bot. 87, 319-324.

Hermans, T., Oware, E., and Caers, J. (2016). Direct prediction of spatially and temporally varying physical properties from time-lapse electrical resistance data. Water Resourc. Res. 52, 7262-7283. doi: 10.1002/2016wr019126

IBM Corp (2015). IBM SPSS Statistics for Windows (Version 23.0). New York, NY: IBM.

ISTA (2018). International Rules for Seed Testing. Bassersdotf: International Seed Testing Association.

Khan, M. A., and Gul, B. (2006). "Halophyte seed germination," in Ecophysiology of High Salinity Tolerant Plants, eds M. Khan and D. Weber (Dordrecht: Springer), 11-30. doi: 10.1007/1-4020-4018-0_2

Khan, M. A., Gul, B., and Weber, D. J. (2001). Seed germination in relation to salinity and temperature in Sarcobatus vermiculatus. Biol. Plant. 45, 133-135.

Khan, M. A., and Gulzar, S. (2003). Germination responses of Sporobolus ioclados: a saline desert grass. J. Arid. Environ. 53, 387-394. doi: 10.1006/jare.2002.1045

Khan, M. A., and Qaiser, M. (2006). Sabkha Ecosystems. Berlin: Springer, 129-153.

Khan, M. A., and Ungar, I. A. (1997). Effect of light, salinity and thermoperiod on seed germination of halophytes. Can. J. Bot. 75, 835-841. doi: 10.1139/b97-093

Khan, M. A., and Ungar, I. A. (1998). Seed germination and dormancy of Polygonum aviculare L. as influenced by salinity, temperature, and gibberellic acid. Seed Sci. Technol. 26, 107-117.

Khan, M. A., and Ungar, I. A. (2001). Alleviation of salinity stress and the response to temperature in two seed morphs of Halopyrum mucronatum (Poaceae). Aust. J. Bot. 49, 777-783.

Khodarahmpour, Z., Ifar, M., and Motamedi, M. (2012). Effects of $\mathrm{NaCl}$ salinity on maize (Zea mays L.). at germination and early seedling stage. Afr. J. Biotechnol. $11,298-304$. 
Larsen, S. U., Bailly, C., Côme, D., and Corbineau, F. (2004). Use of the hydrothermal time model to analyse interacting effects of water and temperature on germination of three grass species. Seed Sci. Res. 14, 35-50.

Li, J., Ma, Z., Liu, Z., Qiao, A., Deng, Y., Wang, W., et al. (2019). Salt resistance of six alpine grass species in Qinghai Province. Pratacult. Sci. 36, 442-449.

Lin, J., Hua, X., Peng, X., Dong, B., and Yan, X. (2018). Germination responses of ryegrass (annual vs. perennial). seed to the interactive effects of temperature and salt-alkali stress. Front. Plant Sci. 9:1458. doi: 10.3389/fpls.2018.01458

Liu, K., Baskin, J. M., Baskin, C. C., Bu, H., Du, G., and Ma, M. (2013). Effect of diurnal fluctuating versus constant temperatures on germination of 445 species from the eastern Tibet Plateau. PLoS One 8:e69364. doi: 10.1371/journal.pone. 0069364

Liu, X., Xu, D., Yang, Z., and Zhang, N. (2017a). Geographic variations in seed germination of Dalbergia odorifera $\mathrm{T}$. Chen in response to temperature. Ind. Crops Prod. 102, 45-50.

Liu, Y., Bortier, M. F., De Boeck, H. J., and Nijs, I. (2017b). Root distribution responses to three-dimensional soil heterogeneity in experimental mesocosms. Plant Soil 421, 353-366.

Liu, Y., De Boeck, H. J., Wellens, M. J., and Nijs, I. (2017c). A simple method to vary soil heterogeneity in three dimensions in experimental mesocosms. Ecol. Res. 32, 287-295. doi: 10.1007/s11284-017-1435-6

Liu, Y., De Boeck, H. J., Li, Z., and Nijs, I. (2019). Unimodal relationship between three-dimensional soil heterogeneity and plant species diversity in experimental mesocosms. Plant Soil 436, 397-411. doi: 10.1007/s11104-019-03938-w

Liu, Y., and Hou, F. (2021). Effects of three-dimensional soil heterogeneity on seed germination in controlled experiments. J. Plant Ecol. 14, 1-9. doi: 10.1093/jpe/ rtaa070

Lu, H., Shen, J., Jin, X., Hannaway, D. B., Daly, C., and Halbleib, M. D. (2008). Determining optimal seeding times for tall fescue using germination studies and spatial climate analysis. Agric. For. Meteorol. 148, 931-941.

Lundholm, J. T. (2010). Relative importance of available energy, environmental heterogeneity, and seed availability for seedling emergence on a limestone pavement. Bot. Botaniq. 88, 1045-1056. doi: 10.1139/b10-077

Maestre, F. T., Cortina, J., Bautista, S., Bellot, J., and Vallejo, R. (2003). Smallscale environmental heterogeneity and spatiotemporal dynamics of seedling establishment in a semiarid degraded ecosystem. Ecosystems 6, 630-643.

Mira, S., Arnal, A., and Perez-Garcia, F. (2017). Habitat-correlated seed germination and morphology in populations of Phillyrea angustifolia L. (Oleaceae). Seed Sci. Res. 27, 50-60.

Mondoni, A., Rossi, G., Orsenigo, S., and Probert, R. J. (2012). Climate warming could shift the timing of seed germination in alpine plants. Ann. Bot. 110, 155-164. doi: 10.1093/aob/mcs097

Nimbalkar, M. S., Pawar, N. V., Pai, S. R., and Dixit, G. B. (2020). Synchronized variations in levels of essential amino acids during germination in grain Amaranth. Braz. J. Bot. 43, 481-491. doi: 10.1007/s40415-020-00624-5

Panuccio, M. R., Jacobsen, S. E., Akhtar, S. S., and Muscolo, A. (2014). Effect of saline water on seed germination and early seedling growth of the halophyte quinoa. AoB Plants 6, lu047. doi: 10.1093/aobpla/plu047

Qu, X., Huang, Z., Baskin, J. M., and Baskin, C. C. (2008). Effect of temperature, light and salinity on seed germination and radicle growth of the geographically widespread halophyte shrub Halocnemum strobilaceum. Ann. Bot. 101, 293299. doi: $10.1093 / \mathrm{aob} / \mathrm{mcm} 047$

Rengasamy, P. (2006). World salinization with emphasis on Australia. J. Exp. Bot. 57, 1017-1023. doi: 10.1093/jxb/erj108

Richmond, C. E., Wethey, D. S., and Woodin, S. A. (2007). Climate change and increased environmental variability: demongraphic responses in an estuarine harpacticoid copepod. Ecol. Model. 209, 189-202. doi: 10.1016/j.ecolmodel. 2007.06.023

Romo, J. T., and Eddleman, L. E. (1995). Use of degree-days in multipletemperature experiments. J. Range Manag. 48, 410-416.

Sayer, A. H., Al-Hussaini, H., and Campbell, A. N. (2017). Experimental analysis of the temperature and concentration profiles in a salinity gradient solar pond with, and without a liquid cover to suppress evaporation. Solar Energy 155, 1354-1365.

Shahba, M. A., Qlan, Y. L., and Lair, K. D. (2008). Improving seed germination of saltgrass under saline conditions. Crop Sci. 48, 756-762. doi: 10.2135/ cropsci2007.07.0382

Shiade, S. R. G., and Boelt, B. (2020). Seed germination and seedling growth parameters in nine tall fescue varieties under salinity stress. Acta Agric. Scand. Sec. B Soil Plant Sci. 70, 485-494.
Spindelböck, J. P., Cook, Z., Daws, M. I., Heegaard, E., Måren, I. E., and Vandvik, V. (2013). Conditional cold avoidance drives between-population variation in germination behavior in Calluna vulgaris. Ann. Bot. 112, 801-810. doi: 10.1093/ $\mathrm{aob} / \mathrm{mct} 142$

Ungar, I. A. (1995). Seed germination and seed-bank ecology of halophytes. Seed Dev. Germin. 9, 599-628. doi: 10.1201/9780203740071-23

Ureta, C., Martorell, C., Hortal, J., and Fornoni, J. (2012). Assessing extinction risks under the combined effects of climate change and human disturbance through the analysis of life-history plasticity. Perspect. Plant Ecol. Evol. Syst. 14, 393-401. doi: 10.1016/j.ppees.2012.09.001

Utset, A., and Borroto, M. (2001). A modelling-GIS approach for assessing irrigation effects on soil salinization under global warming conditions. Agric. Water Manag. 50, 53-63. doi: 10.1016/s0378-3774(01)00090-7

Vu, W. T., Chang, P., Moriuchi, K. S., and Friesen, M. L. (2015). Genetic variation of transgenerational plasticity of offspring germination in response to salinity stress and the seed transcriptome of Medicago truncatula. BMC Evol. Biol. 15:59. doi: 10.1186/s12862-015-0322-4

Walck, J. L., Hidayati, S. N., Dixon, K. W., Thompson, K., and Poschlod, P. (2011). Climate change and plant regeneration from seed. Glob. Chang. Biol. $17,2145-2161$.

Wang, H., Wu, Z., Chen, Y., Yang, C., and Shi, D. (2011). Effects of salt and alkali stresses on growth and ion balance in rice (Oryza sativa L.). Plant Soil Environ. 57, 286-294.

Wu, G., Jiao, Q., and Shui, Q. (2015). Effect of salinity on seed germination, seedling growth, and inorganic and organic solutes accumulation in sunflower (Helianthus annuus L.). Plant Soil Environ. 5, 220-226. doi: 10.17221/22/2015pse

Xu, S., Hu, B., He, Z., Ma, F., Feng, J., Shen, W., et al. (2011). Enhancement of salinity tolerance during rice seed germination by presoaking with hemoglobin. Int. J. Mol. Sci. 12, 2488-2501. doi: 10.3390/ijms12042488

Yang, H., Huang, Z., Baskin, C. C., Baskin, J. M., Cao, Z., Zhu, X., et al. (2009). Responses of caryopsis germination, early seedling growth and ramet clonal growth of Bromus inermis to soil salinity. Plant Soil 316, 265-275. doi: 10.1007/ s11104-008-9778-y

Zhang, H., McGill, C. R., Irving, L. J., Kemp, P. D., and Zhou, D. (2013). A modified thermal time model to predict germination rate of ryegrass and tall fescue at constant temperatures. Crop Sci. 53, 240-249. doi: 10.2135/cropsci2012.02. 0085

Zhang, Q., and Dai, W. (2019). "Plant response to salinity stress," in Stress Physiology of Woody Plants, ed. W. Dai (Boca Raton: CRC Press), 155-173. doi: 10.1201/9780429190476-7

Zhang, R., Luo, K., Chen, D., Baskin, J., Baskin, C., Wang, Y., et al. (2020). Comparison of thermal and hydrotime requirements for seed germination of seven Stipa species from cool and warm habitats. Front. Plant Sci. 11:560714. doi: 10.3389/fpls.2020.560714

Zhang, T., Qi, J., Gao, Y., Ouyang, Z., Zeng, S., and Zhao, B. (2015a). Detecting soil salinity with MODIS time series VI data. Ecol. Indic. 52, 480-489. doi: 10.1016/j.ecolind.2015.01.004

Zhang, T., Song, J., Fan, J., and Feng, G. (2015b). Effects of salinewaterlogging and dryness/moist alternations on seed germination of halophyte and xerophyte. Plant Spec. Biol. 30, 231-236. doi: 10.1111/1442-1984.1 2056

Conflict of Interest: The authors declare that the research was conducted in the absence of any commercial or financial relationships that could be construed as a potential conflict of interest.

Publisher's Note: All claims expressed in this article are solely those of the authors and do not necessarily represent those of their affiliated organizations, or those of the publisher, the editors and the reviewers. Any product that may be evaluated in this article, or claim that may be made by its manufacturer, is not guaranteed or endorsed by the publisher.

Copyright (c) 2021 Liu, Zhang, De Boeck and Hou. This is an open-access article distributed under the terms of the Creative Commons Attribution License (CC BY). The use, distribution or reproduction in other forums is permitted, provided the original author(s) and the copyright owner(s) are credited and that the original publication in this journal is cited, in accordance with accepted academic practice. No use, distribution or reproduction is permitted which does not comply with these terms. 